\title{
Hydrogen Peroxide Direct Synthesis: Selectivity Enhancement in a Trickle Bed Reactor
}

\author{
Pierdomenico Biasi, ${ }^{\dagger, \S, \perp}$ Federica Menegazzo, ${ }^{\dagger}$ Francesco Pinna, ${ }^{\dagger}$ Kari Eränen, ${ }^{\dagger}$ Paolo Canu, ${ }^{*}, \S$ and \\ Tapio O. Salmi* ${ }^{\dagger}$ \\ Process Chemistry Centre (PCC), Laboratory of Industrial Chemistry and Reaction Engineering, Åbo Akademi, \\ Biskopsgatan 8, Turku 20500 Finland, Dipartimento di Chimica, Università di Venezia, and Consorzio INSTM, \\ 30123 Venezia, Italy, and Dipartimento di Principi e Impianti di Ingegneria Chimica "I. Sorgato" (DIPIC), \\ University of Padova, via Marzolo 9, 35131, Padova, Italy
}

$\mathrm{H}_{2} \mathrm{O}_{2}$ direct synthesis over a palladium catalyst based on sulfated ceria $(\mathrm{Pd}-\mathrm{CeS})$ has been studied in a trickle-bed reactor at $-10{ }^{\circ} \mathrm{C}$. The combined effect of liquid and gas flow rates was studied by independent variations. The maximum productivity and selectivity was always found at flow rate combinations intermediate within the investigated range. The reactor operated under pressure and its effect was investigated (10 and 20 bar), resulting in a significant gain in selectivity. Selectivity up to $80 \%$ has been measured at the highest pressure tested ( 20 bars), liquid flow rate of $2 \mathrm{~mL} / \mathrm{min}$, and $6 \mathrm{~mL} / \mathrm{min}$ gas flow rate. The maximum production rate measured was $0.0035 \mathrm{mmol} / \mathrm{min}$ with $0.5 \mathrm{~mL} / \mathrm{min}$ liquid flow rate and $2.7 \mathrm{~mL} / \mathrm{min}$ gas flow rate. Relevance of direct water formation has been isolated by independently investigating $\mathrm{H}_{2} \mathrm{O}_{2}$ decomposition and hydrogenation. Results indicate directions of further performance improvements and the importance of reactor type and operation.

\section{Introduction}

Hydrogen peroxide is considered an attractive, environmentally compatible oxidant with several nonselective applications such as the paper and textile industries and wastewater treatment. The direct synthesis from its elements is in principle the best method for producing $\mathrm{H}_{2} \mathrm{O}_{2}$, but still insufficiently developed. Direct synthesis could result in a simpler process and plants. It would not require extraction or concentration of $\mathrm{H}_{2} \mathrm{O}_{2}$ and the purification steps would be simplified; the capital investment and operating costs are expected to be lower than those for the anthraquinone autoxidation (AO) process. Direct synthesis could be relevant for the chemical industry also, in view of an integration with other processes such as the HPPO process. Onsite $\mathrm{H}_{2} \mathrm{O}_{2}$ synthesis would reduce or eliminate the costs and hazards of transport and handling of concentrated solutions. Both academia and industry have investigated direct synthesis, and important patents are available $\mathrm{e}^{1-10}$ and continuously appear. Productivity, selectivity, and safety issues still need improvement for industrial applicability. Although the catalytic direct synthesis has been known since $1914,{ }^{11}$ safety issues supported the AO process almost exclusively. ${ }^{12}$ The direct path attracted renewed interest after 1980 following environmental concerns. Since then, the process has been extensively investigated, leading to a large number of publications in the past few years. ${ }^{12-33}$ Several patents have been issued since the $1990 \mathrm{~s},{ }^{1-10}$ but no stable industrial application is known, although one has been announced. ${ }^{13}$

Though simple in principle, direct formation is connected to thermodynamically favored side reactions (Scheme 1). Each one may be affected by the catalyst, the additives in the reaction

\footnotetext{
* To whom correspondence should be addressed. E-mail: paolo. canu@unipd.it (P.C.), tsalmi@abo.fi (T.S.).

Åbo Akademi.

Università di Venezia and Consorzio INSTM.

$\S$ University of Padova.

${ }^{\perp}$ Present address: Process Chemistry Centre (PCC), Laboratory of Industrial Chemistry and Reaction Engineering, Åbo Akademi, Biskopsgatan 8, Turku 20500 Finland.
}

medium, and the operative conditions, resulting in different yields and selectivities. $\mathrm{H}_{2} \mathrm{O}_{2}$ hydrogenation and decomposition are unwanted reactions, but unfortunately favored by most of the catalysts active for synthesis. The present work is based on successful findings by Menegazzo and co-workers, ${ }^{14}$ who synthesized a number of promising catalysts, based on $\mathrm{Pd},{ }^{14,15}$ $\mathrm{Pd}-\mathrm{Au}^{14,16,17}$ and Pd$-\mathrm{Pt}{ }^{17}$ Here we investigate the opportunities of engineering the reaction, raising the scale of investigation and implementing continuous operation. We used a trickle bed reactor (TBR), an arrangement that can be industrially scalable. Advantages include minimization of gas hold-up (explosion hazard) while still allowing for a large production potential, thanks to continuous operation. In addition, gas and liquid residence time can be independently manipulated to affect the extent of reaction and the gas-liquid mass transfer effectiveness (a compensation for small reagents solubility, even lower if operating in the nonexplosive region). Further, we will show that significant enhancements of selectivity can be obtained in a TBR with respect to batch operation with the same catalyst, at comparable conditions.

\section{Experimental Section}

Materials. $\left(\mathrm{NH}_{4}\right)_{2} \mathrm{Ce}\left(\mathrm{NO}_{3}\right)_{6}$ (Sigma-Aldrich) and $\left(\mathrm{NH}_{4}\right)_{2} \mathrm{SO}_{4}$ (Merck) were used for catalyst synthesis as received. Methanol

Scheme 1. Reactions Involved in the Direct Synthesis of $\mathrm{H}_{2} \mathrm{O}_{2}$

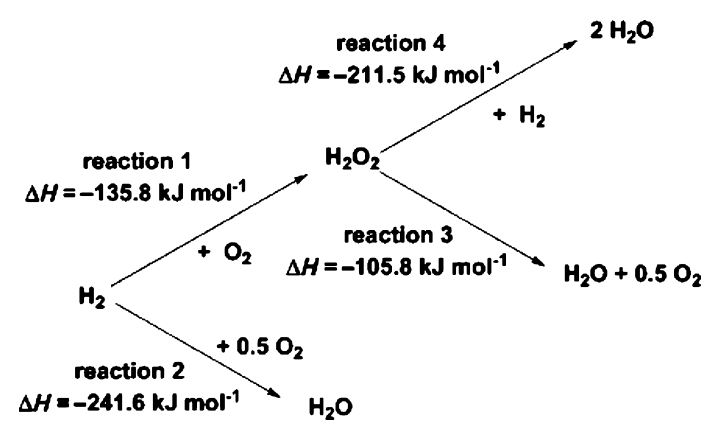




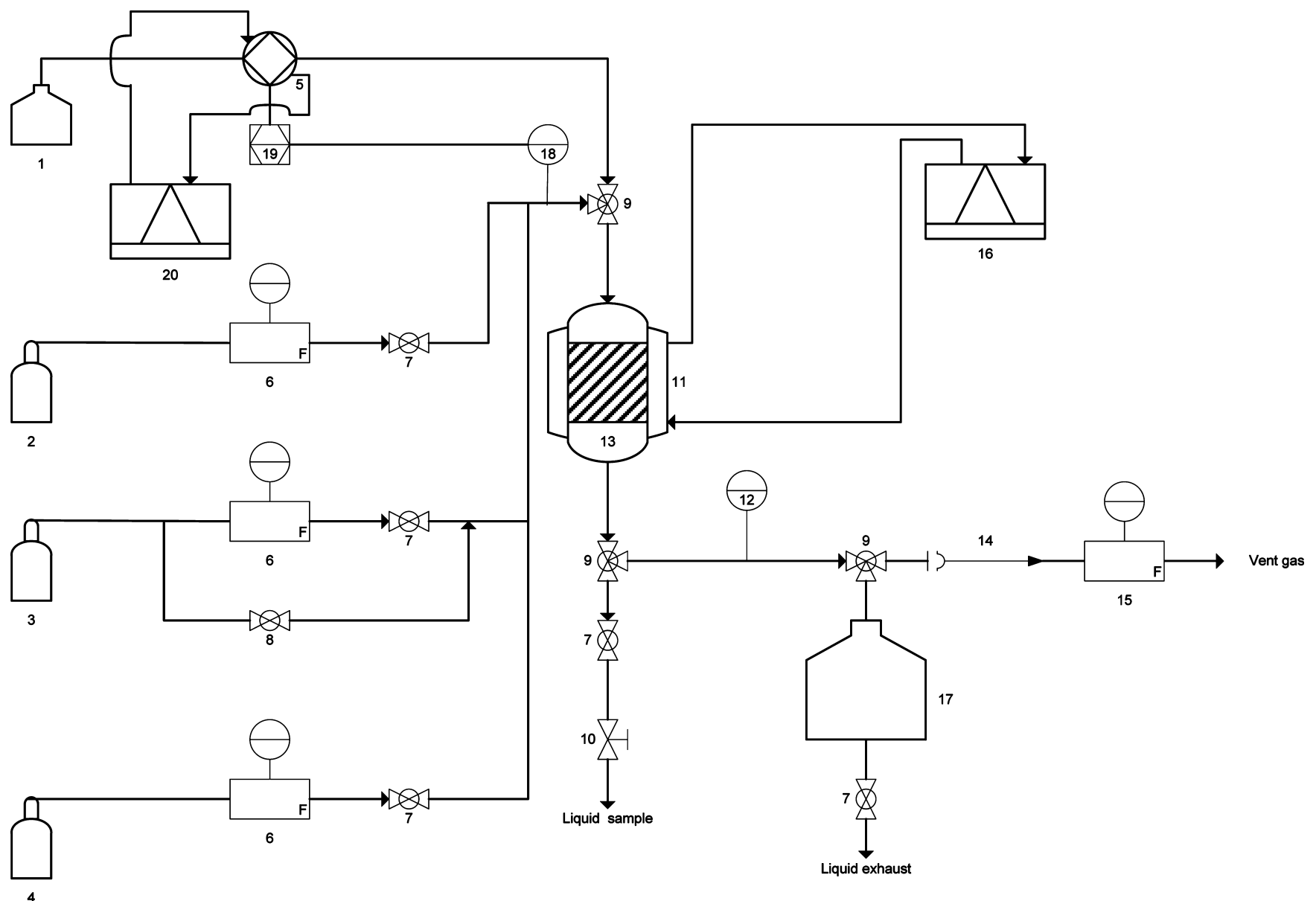

Figure 1. Schematic of the experimental apparatus. (1) Liquid solvent supply. (2, 3, 4) Gas bottles: $\mathrm{N}_{2}, \mathrm{CO}_{2} / \mathrm{H}_{2}(97.5 / 2.5 \%)$, and $\mathrm{O}_{2}$, respectively. (5) Syringe pump. (6) Mass flow controller (MFC). (7, 8) On/off and bypass valves. (10) Liquid sampling. (11, 16) External cooling with chiller. (12, 18) Pressure gauges. (13) Trickle bed reactor (TBR). (14) Rupture disk. (15) Back pressure controller (BPC). (17) Liquid collection. (19) Computer. (20) Chiller.

for HPLC was used as reaction medium (J.T. Baker, 99.99\%) and $\mathrm{H}_{2} \mathrm{O}_{2} 30 \%$ w/w (Merck) was used for decomposition tests, while analyses used potassium iodide (Sigma-Aldrich), Hydranal-Composite 2 (Fluka), dry methanol for KFT (Fluka), acetic acid (Sigma-Aldrich), sodium thiosulfate penta-hydrate $(99.5 \%$, Sigma-Aldrich), starch (Sigma-Aldrich), and potassium dichromate (Riedel de Haën). Catalyst has been prepared as already reported ${ }^{14}$ and pre-reduced in situ before use. Preliminary tests of $\mathrm{H}_{2} \mathrm{O}_{2}$ decomposition were carried out to ascertain that the support alone does not decompose $\mathrm{H}_{2} \mathrm{O}_{2}$. We used pure calcined sulfated ceria at $20^{\circ} \mathrm{C}, 1$ bar for 5 h. ${ }^{14}$

Reactor Setup for the Experiments. A cocurrent, downflow TBR was developed. In addition to the motivations already mentioned, the TBR allows short liquid residence time if required for selectivity. It is a steady-state reactor, so that chemical analysis has no limitation on the sampled quantity and does not affect the reactor operation.

The experimental reactor setup is shown schematically in Figure 1. The reactor is made of AISI 316 stainless steel, 30 $\mathrm{cm}$ long, $1.5 \mathrm{~cm}$ I.D., and internally lined with Teflon $(1.15 \mathrm{~cm}$ final I.D.) to prevent $\mathrm{H}_{2} \mathrm{O}_{2}$ decomposition due to accessible $\mathrm{Fe}^{3+}$ ions. The reactor can accommodate a catalyst bed up to $20 \mathrm{~cm}$ long. An external chiller (Grant LT D6G) allows for working temperatures between -20 and $60{ }^{\circ} \mathrm{C}$. Three mass flow controllers (MFC; Brooks 5850 series) are used to independently feed the gases: $\mathrm{N}_{2}, \mathrm{CO}_{2} / \mathrm{H}_{2} 97.5 / 2.5 \%$, and $\mathrm{O}_{2}$ (AGA gas). MFC have been calibrated on actual mass flow; volumetric flow rates reported in the Figures are calculated with mixture densities determined with a Redlich-Kwong-Soave equation of state with Boston-Mathias modification, through the Aspen Properties code. The pressure inside the reactor is controlled and regulated with a back pressure controller (BPC; Brooks 5866 series). A rupture disk is located before the BPC for safety reasons. A bypass is used to achieve the desired pressure inside the reactor more rapidly. The liquid phase is fed in through a syringe pump (Teledyne ISCO model 500D), connected to a pressure transducer and computer controlled. The syringe temperature can be controlled. Gas and liquids mix at a T-connection before the reactor. A regulation valve is used to sample the instantaneous liquid phase, while a $1.5 \mathrm{~L}$ tank provides gas-liquid separation, accumulating all the liquid product. All the piping is made of stainless steel AISI 316, $1 / 8$ in. size. The catalyst bed $(0.5 \mathrm{~cm}$ long $)$ is placed between two quartz wool plugs. Above the upstream quartz wool plug, quartz sand is used to improve mixing. Temperature inside the reactor is measured with a K-thermocouple before the catalyst bed. The apparatus is in a fume hood, with a $\mathrm{H}_{2}$ sensor that can automatically switch off $\mathrm{H}_{2}$ flow to the reactor.

$\mathrm{H}_{2} \mathrm{O}_{2}$ Experiments and Analyses. $\mathrm{H}_{2} \mathrm{O}_{2}$ decomposition and hydrogenation were investigated first, at 10 bar and $-10{ }^{\circ} \mathrm{C}$, with $0.5 \% \mathrm{H}_{2} \mathrm{O}_{2}$ in methanol as the liquid phase, varying its flow rate $(0.5,1$, and $2 \mathrm{~mL} / \mathrm{min})$. The gas mixture was either $\mathrm{N}_{2} / \mathrm{CO}_{2}\left(20 / 80 \%\right.$ mol) for pure decomposition, or $\mathrm{H}_{2} / \mathrm{N}_{2} / \mathrm{CO}_{2}$ $(2 / 18 / 80 \% \mathrm{~mol})$ for hydrogenation experiments $\left(\mathrm{N}_{2}\right.$ replaces $\left.\mathrm{O}_{2}\right)$, varying its flow rates $(0.1,1,2,2.7,4,6,9$, and $12 \mathrm{~mL} / \mathrm{min})$. 
The experiments of direct synthesis are carried out at 10 or 20 bar and $-10{ }^{\circ} \mathrm{C}$, in methanol, with the same flow rates used above. Gas composition was $\mathrm{H}_{2} / \mathrm{O}_{2} / \mathrm{CO}_{2}(2 / 18 / 80 \% \mathrm{~mol})$. The total gas flow rates vary $(1,2,2.7,4,6,9 \mathrm{~mL} / \mathrm{min}$ at both pressures; also $12 \mathrm{~mL} / \mathrm{min}$ at $10 \mathrm{bar}$ ). The volumetric total flow rates correspond to specific mass flow rates ranging between 0.063 and $0.254 \mathrm{~kg} / \mathrm{m}^{2} \mathrm{~s}$ for the liquid and between 0.0021 and $0.0433 \mathrm{~kg} / \mathrm{m}^{2} \mathrm{~s}$ for the gas. According to typical flow maps, ${ }^{29,30}$ all the experiments have been carried out well in the trickling regime.

We chose to operate the reactor at $-10{ }^{\circ} \mathrm{C}$ because (1) the decomposition and hydrogenation of $\mathrm{H}_{2} \mathrm{O}_{2}$ are slower, while synthesis is less affected by temperature, (2) solubility of $\mathrm{CO}_{2}$ in methanol rises, thus increasing hydrogen solubility in the mixture, ${ }^{34}$ (3) it is a low temperature industrially feasible without significant increase of costs, and (4) catalyst and mixture stability increase.

New catalyst is introduced in the reactor without pretreatment. In situ reduction with $\mathrm{H}_{2}(20 \mathrm{~mL} / \mathrm{min})$ at room $\mathrm{T}$ and $\mathrm{P}$ for $1 \mathrm{~h}$ follows. The reduction state $\left(\mathrm{Pd}^{0}\right)$ is expected to remain after the liquid feed is started and pressurization with a mixture $\mathrm{CO}_{2} /$ $\mathrm{H}_{2}(97.5 / 2.5 \% \mathrm{~mol})$ is achieved. Eventually, $\mathrm{O}_{2}$ is fed also and the oxidation state becomes questionable. Although water formation (experimentally measured) is considered ${ }^{19,28,31,32}$ an indication of $\mathrm{Pd}^{2+}$ in the absence of promoters (e.g., halide ions and acids), their addition causes $\mathrm{Pd}^{2+}$ to be active for $\mathrm{H}_{2} \mathrm{O}_{2}$ production ${ }^{14-16,19,20,31-33}$ as well. The actual oxidation state in the presence of both $\mathrm{O}_{2}$ and $\mathrm{H}_{2}$ may vary. In addition, their concentration varies along the bed due to the reaction and different solubility. The $\mathrm{O}_{2} / \mathrm{H}_{2}$ ratio increases along the bed, possibly changing the local $\mathrm{Pd}$ oxidation state. On these arguments, consideration on the mechanism can be developed, as discussed later.

During each single test, the liquid phase is sampled at the reactor exit, and water (volumetric Karl Fischer) and $\mathrm{H}_{2} \mathrm{O}_{2}$ (iodometric titration) concentrations are measured. Water content is also measured prior to each experiment, before feeding $\mathrm{O}_{2}$. Production rate is defined as mol of $\mathrm{H}_{2} \mathrm{O}_{2}$ produced/min, and it is given by the $\mathrm{H}_{2} \mathrm{O}_{2}$ concentration measured in the liquid sampled (almost pure methanol, after flashing) times the methanol flow rate set at its MFC, as representative of the liquid flow rate. Selectivity is defined as $100 \times\left[\mathrm{H}_{2} \mathrm{O}_{2}\right] /\left(\left[\mathrm{H}_{2} \mathrm{O}_{2}\right]+\right.$ $\left[\mathrm{H}_{2} \mathrm{O}\right]_{\text {prod }}$ ); it is equal to the moles of $\mathrm{H}_{2} \mathrm{O}_{2}$ produced, divided by the moles of $\mathrm{H}_{2}$ consumed.

The catalyst stability has been assessed by carrying out cycles of $16 \mathrm{~h}$ operation (gas flow rate $=2.7 \mathrm{~mL} / \mathrm{min}$ and liquid flow rate $=1 \mathrm{~mL} / \mathrm{min}$ ), and $8 \mathrm{~h}$ (overnight) decompression and conditioning with $\mathrm{N}_{2}$, for a total of 5 times. During each 16-h operation cycle, liquid samples at times 4, 10, $16 \mathrm{~h}$ were collected and production rate and selectivity were measured.

\section{Results and Discussion}

$\mathrm{H}_{2} \mathrm{O}_{2}$ Hydrogenation and Decomposition. Unfortunately, palladium catalyzes $\mathrm{H}_{2} \mathrm{O}_{2}$ decomposition and hydrogenation (reactions 3 and 4 of Scheme 1) in addition to its direct synthesis. To quantify the degree of $\mathrm{H}_{2} \mathrm{O}_{2}$ loss by decomposition and hydrogenation, experiments were carried out with the same catalyst and under the same operative conditions as the synthesis. Results in the TBR with different gas and liquid flow rates are shown in Figures 2 and 3 as percentage of $\mathrm{H}_{2} \mathrm{O}_{2}$ loss. Qualitatively, both degradation paths (with/without $\mathrm{H}_{2}$ ) are affected similarly by either gas or liquid flow rates. A larger liquid flow rate implies a smaller contact time on the catalyst, then less degradation occurs. The gas flow rate is not expected

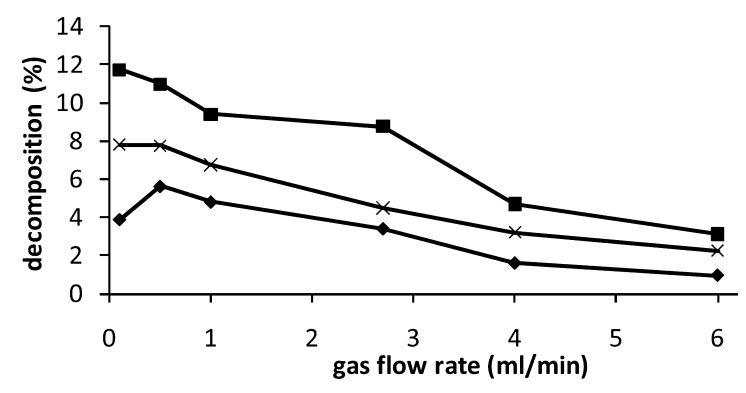

Figure 2. Simple decomposition of $0.5 \%$ of $\mathrm{H}_{2} \mathrm{O}_{2}$ in methanol at 10 bar and $-10^{\circ} \mathrm{C}$. Methanol flow rate: $0.5 \mathrm{~mL} / \mathrm{min}(\square), 1 \mathrm{~mL} / \mathrm{min}(\times), 2 \mathrm{~mL} /$ $\min (\diamond)$.

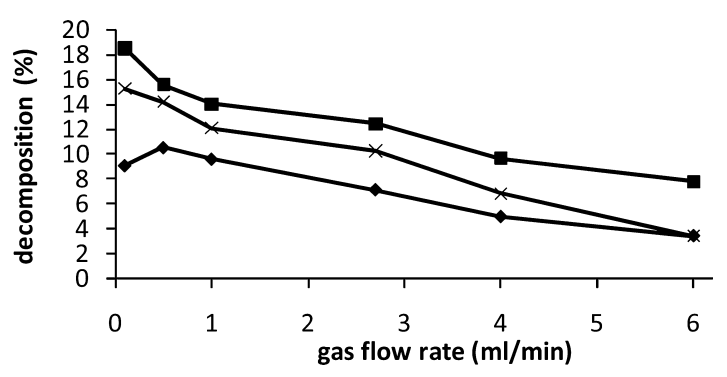

Figure 3. Hydrogenation and decomposition of $0.5 \%$ of $\mathrm{H}_{2} \mathrm{O}_{2}$ in methanol at 10 bar and $-10^{\circ} \mathrm{C}$. Methanol flow rate: $0.5 \mathrm{~mL} / \mathrm{min}(\mathbf{\square}), 1 \mathrm{~mL} / \mathrm{min}(\times)$, $2 \mathrm{~mL} / \mathrm{min}(\bullet)$.

to directly affect the reaction extent, which takes place at the liquid-solid interface. Indirectly, a larger gas flow rate has two effects: (i) it can increase the mass transfer rate between gas and liquid (i.e., higher conversion), and (ii) it reduces the volumetric fraction of liquid, causing larger liquid velocities, then lower liquid/solid contact time (i.e., a smaller conversion). The first effect is negligible, unless the liquid flow rate is large, requiring a comparatively large transfer rate from the gas. Soon after the minimum gas flow rate, the second effect prevails all the time. We conclude that larger gas flow rates almost always cause a lower conversion.

$\mathrm{H}_{2}$ always increases the $\mathrm{H}_{2} \mathrm{O}_{2}$ degradation. Overall, both paths can decompose up to $20 \%$ of the $\mathrm{H}_{2} \mathrm{O}_{2}$ available, at the low $0.5 \%$ mol concentration, with a minimum $>1 \%$ at the highest flow rates. These values provide an upper bound for the synthesis, given that $\mathrm{H}_{2} \mathrm{O}_{2}$ is gradually produced along the bed. Hydrogenation accounts for approximately $1 / 3$ of the total degradation, suggesting that synthesis can be viable, if its rate can be sufficiently higher than the significant degradation processes.

The combination of $2 \mathrm{~mL} / \mathrm{min}$ of liquid and $0.1 \mathrm{~mL} / \mathrm{min}$ of gas, i.e., the maximum liquid and minimum gas flow rates, suffers mass transfer limitations that likely prevent the achievement of $\mathrm{H}_{2}$ and $\mathrm{O}_{2}$ dissolution equilibrium, also indicated by a sensible decrease of pressure drop across the bed; accordingly, it was not used in subsequent tests.

Interestingly, if the amount of water formed during $\mathrm{H}_{2} \mathrm{O}_{2}$ synthesis, under the same conditions, is higher than the maximum obtained during the hydrogenation and decomposition experiments, the excess water formed is to be ascribed to the direct water formation reaction (Scheme 1, reaction 2), which competes with $\mathrm{H}_{2} \mathrm{O}_{2}$ synthesis.

$\mathrm{H}_{2} \mathrm{O}_{2}$ Synthesis. The results of the experiments to produce $\mathrm{H}_{2} \mathrm{O}_{2}$ from its elements in a TBR are shown in Figures 4 to 8. Different gas and liquid flow rates are investigated, reporting either $\mathrm{H}_{2} \mathrm{O}_{2}$ production rate or selectivity, as previously defined. Two sets of experiments, at 10 and 20 bar, are reported. 


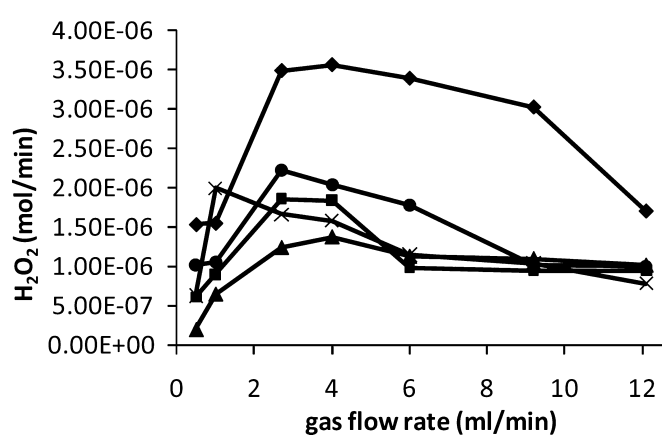

Figure 4. Production rate of $\mathrm{H}_{2} \mathrm{O}_{2}$. Combined effect of gas and liquid flow rates at 10 bar and $-10{ }^{\circ} \mathrm{C}$. Methanol flow rate: $0.3 \mathrm{~mL} / \mathrm{min}(\times), 0.5 \mathrm{~mL} /$ $\min (\diamond), 0.75 \mathrm{~mL} / \mathrm{min}(\bullet), 1 \mathrm{~mL} / \mathrm{min}(\boldsymbol{\square}), 2 \mathrm{~mL} / \mathrm{min}(\boldsymbol{\bullet})$.

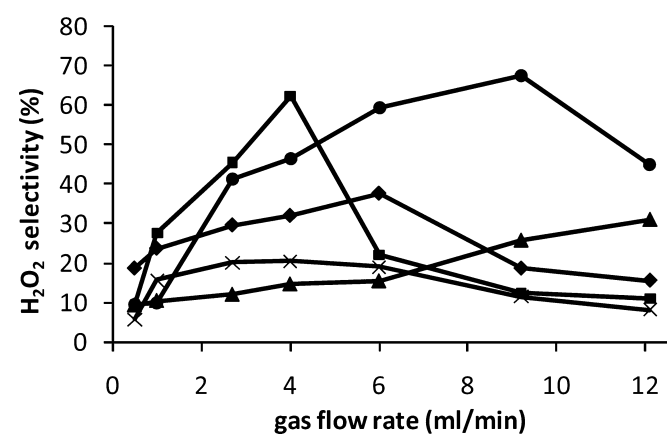

Figure 5. Selectivity of hydrogen peroxide. Same conditions as Figure 4.

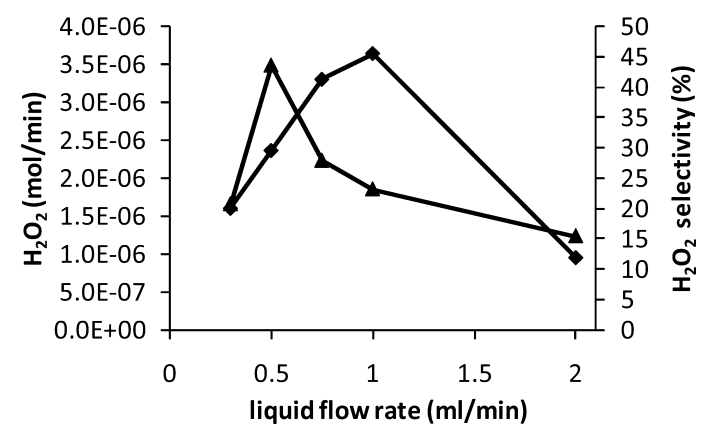

Figure 6. Production rate $(\boldsymbol{\Delta})$ and selectivity $(\boldsymbol{)})$ at a constant gas flow rate $(2.7 \mathrm{~mL} / \mathrm{min})$, varying the liquid flow rate. $T=-10{ }^{\circ} \mathrm{C}, P=10$ bar.

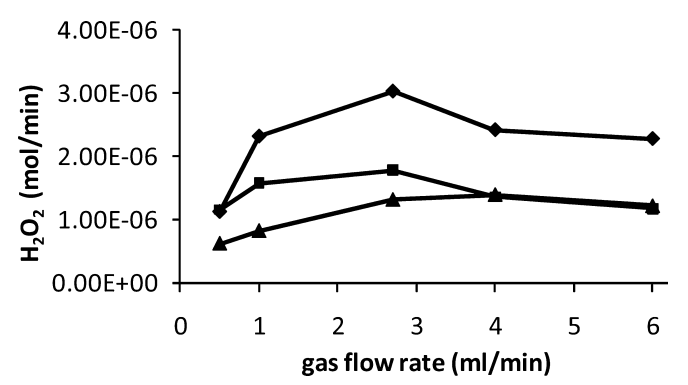

Figure 7. Production rate of $\mathrm{H}_{2} \mathrm{O}_{2}$. Combined effect of gas and liquid flow rates at 20 bar and $-10{ }^{\circ} \mathrm{C}$. Methanol flow rate: $0.5 \mathrm{~mL} / \mathrm{min}(\diamond), 1 \mathrm{~mL} / \mathrm{min}$ (অ), $2 \mathrm{~mL} / \mathrm{min}(\mathbf{\Lambda})$.

The production rate at $10 \mathrm{bar},-10{ }^{\circ} \mathrm{C}$ (Figure 4) is larger with a small liquid flow rate. Recalling that productivity is defined as the product of liquid flow rate times the outlet $\mathrm{H}_{2} \mathrm{O}_{2}$ concentration, its increase with smaller liquid flow rate implies that the kinetics grows more than linearly with residence time. Further, productivity varies with gas flow rate, always going through a maximum, i.e., an optimum gas flow rate can be identified for every liquid flow rate examined. An optimum can

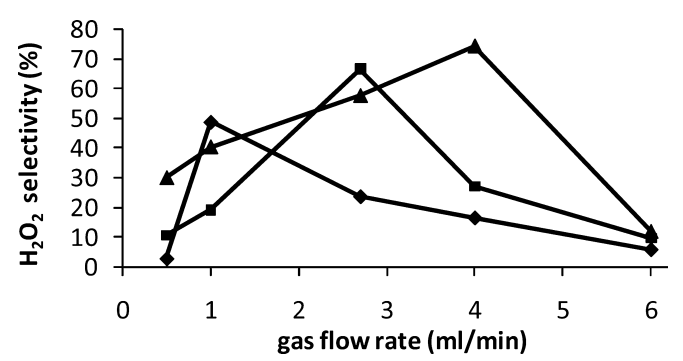

Figure 8. Selectivity of $\mathrm{H}_{2} \mathrm{O}_{2}$. Same conditions as Figure 7.

be identified with respect to liquid flow rate also. The maximum production rate is measured with a small flow rate $(0.5 \mathrm{~mL} /$ min), but not the lowest tested $(0.3 \mathrm{~mL} / \mathrm{min})$, implying a nonlinear effect.

As discussed through the mechanism of Scheme 1, selectivity due to the competing reactions is a major issue for direct synthesis. Selectivity in the previous experiments is shown in Figure 5. Again, the effect of both flow rates is dramatic, with optimum selectivity at intermediate values. At small gas flow rates the selectivity is always quite poor. The maximum selectivity was achieved with liquid flow rates of 1 and 0.75 $\mathrm{mL} / \mathrm{min}$, but at correspondingly different gas flow rates. Note that conditions for good production rate do not always match those required for a high selectivity.

As previously discussed concerning hydrogenation and decomposition experiments, we speculate that selectivity lower than $80 \%$ indicates excess water formation directly from $\mathrm{H}_{2}$ and $\mathrm{O}_{2}$. Selectivity in these experiments is always below $80 \%$, but at the small liquid and gas flow rates the contribution is quite significant. We conclude that the mechanism for $\mathrm{H}_{2} \mathrm{O}_{2}$ direct synthesis must account for the parallel water formation and the decomposition of $\mathrm{H}_{2} \mathrm{O}_{2}$ to water, usually neglected. ${ }^{14-17}$

The nonlinear effect of liquid flow rate is evident from Figure 6 , where experimental results at a fixed gas flow rate $(2.7 \mathrm{~mL} /$ $\mathrm{min}$ ) are shown. A maximum in both selectivity and productivity is observed, but at different conditions. The liquid flow rate affects contact times with the catalyst and likely its wetting. Interestingly, a TBR allows independent setting of liquid and gas flow rates (within a range that keeps the same hydrodynamic regime) to maximize either productivity or selectivity. Results indicate that we successfully took advantage of the short contact time that can be achieved (order of a few seconds) and the possibility of finely tuning it to select an optimal path through the mechanism. This is obtained mostly by preventing side reactions from occurring through a limitation of the contact between the catalyst and the reacting mixture. Figure 6 clearly shows that a short enough contact time is required to achieve a good selectivity, but excessively short will compromise the production rate. On the other side, a longer contact time, which maximizes the production rate, results in a detrimental effect on selectivity.

Consideration of the residence time can be reformulated in terms of reaction mechanism progress along the catalyst bed. The above evidence allows speculation that only reactions of $\mathrm{H}_{2} \mathrm{O}_{2}$ direct synthesis and water formation occur in the first part of the catalytic bed, due to the low concentration of $\mathrm{H}_{2} \mathrm{O}_{2}$. It is reported ${ }^{19,28,31,32}$ that completely oxidized $\mathrm{Pd}^{2+}$ (likely in the form of $\mathrm{PdO}$ ) preferentially supports water formation instead of $\mathrm{H}_{2} \mathrm{O}_{2}$ synthesis in the absence of promoters (as we operate). Since oxygen is fed largely exceeding $\mathrm{H}_{2}$, we speculate that a significant fraction of the irregular palladium clusters could be indeed $\mathrm{Pd}^{2+}$, notwithstanding the initial reduction pretreatment, thus favoring water formation. Therefore dissociative adsorption 
of hydrogen is reduced, and hence the chance to have direct synthesis. ${ }^{19,28,31-33}$ Hydrogen is more likely to react with the oxygen present on the $\mathrm{Pd}^{2+}$ surface than with the inner part of the Pd cluster, with the condition mentioned above $\mathrm{e}^{16,17,19,20,33,35}$ (i.e., an acidic solution or the presence of halides). When contact time between liquid and solid phases is longer, all the reactions occur, adding further $\mathrm{H}_{2} \mathrm{O}_{2}$ degradation paths. For intermediate gas and liquid flow rates, production rate is higher and selectivity achieves very interesting values. Gas solubilization in the liquid phase plays a key role; it can be modified by using solvent that selectively increases $\mathrm{H}_{2}$ solubility, ${ }^{34}$ but also the pressure and the ratio between gas and liquid flow rates can affect the concentration of $\mathrm{H}_{2}$ and $\mathrm{O}_{2}$ in the liquid phase.

These observations allow concluding that operative condition in the TBR may help in controlling the reaction network, in addition to suitable catalysts, linking the catalyst and the reactor design and operation. It has been proved that operative conditions play a major role in driving the reactions toward high selectivity for hydrogen peroxide. The results suggest that reactor design and operation may be crucial to improve productivity and selectivity in $\mathrm{H}_{2} \mathrm{O}_{2}$ synthesis, together with developing better catalysts.

$\mathbf{H}_{2} \mathrm{O}_{2}$ Synthesis: Effect of Pressure. The pressure changes the gas solubility; it can also affect the hydrodynamics. It has been studied observing the $\mathrm{H}_{2} \mathrm{O}_{2}$ production rate and selectivity, replicating some of the previous experiments (at 10 bar) at 20 bar, always at $-10{ }^{\circ} \mathrm{C}$. Results at 20 bar are reported in Figures 7 and 8 , for productivity and selectivity, respectively. They must be compared with Figures 4 and 5 for results at 10 bar. Note that the higher pressure requires a larger mass flow rate to achieve the same volumetric gas flow rate, because of a higher density. Production rate (Figure 7) behaves similarly to the case of 10 bar (Figures 4), with a clear maximum with respect to the gas flow rates. The lowest liquid flow rate used $(0.5 \mathrm{~mL} /$ min) results in the maximum productivity, slightly smaller than that obtained at 10 bar, unexpectedly, given the larger concentration of reagents determined by a higher pressure. We can also observe that the higher pressure shifts the maximum of productivity to lower gas flow rates, but the shift decreases with higher liquid flow rates. This may simply reflect that data are better comparable in terms of equal gas mass flow rates. At the same time, the role of pressure with small gas flow rates is to support an increase of production rate. This is quite clear except for the case of $0.5 \mathrm{~mL} / \mathrm{min}$ liquid flow rate and the smaller gas flow rate, where an inversion has been measured. The inverse is observed at large gas flow rate, where an increase of pressure apparently leads to a smaller production rate. In other words, we can say that the gain in production rate of hydrogen peroxide achieved with smaller liquid flow rates is reduced by a larger pressure.

Results for selectivity at 20 bar are shown in Figure 8 and compare with Figure 5 (10 bars). Interestingly, we always measured a significant increase in selectivity with pressure (particularly for the minimum and maximum liquid flow rates) and a shift of the best operating conditions. The maximum selectivity increases with liquid flow rate, approaching $80 \%$ of $2 \mathrm{~mL} / \mathrm{min}$, with a net gain of approximately $50 \%$ with respect to 10 bar. As before, the highest selectivity is achieved at conditions where the productivity is quite low. The maximum of selectivity is reached with a lower gas flow rate at 20 bar, compared to 10 bar, approaching mass flow rates comparable to those of the 10 bar case.

Catalyst Stability. The stability of the catalyst has been evaluated as described above. Results are shown in Figure 9,

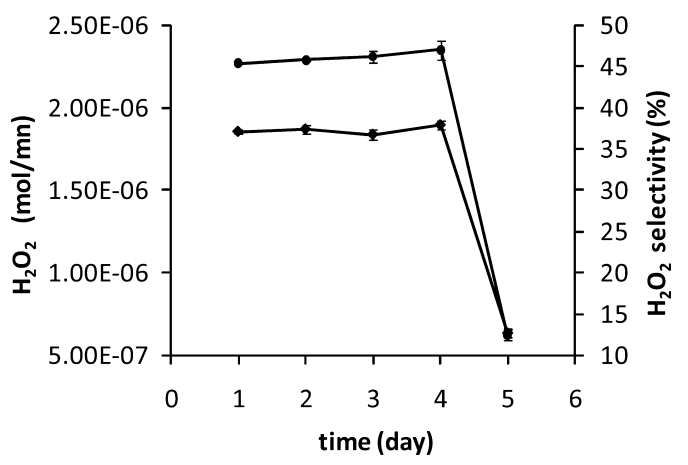

Figure 9. Production rate $(\bullet)$ and selectivity $(\bullet)$. Catalyst stability at 10 bar and $-10{ }^{\circ} \mathrm{C}$.

where each point is the average of samplings at 4,10 , and $16 \mathrm{~h}$ within the same day. The amount of $\mathrm{H}_{2} \mathrm{O}_{2}$ produced remains quite constant within the same day and among different days, with a low variance $(<2 \%)$, until a sudden drop after the fifth cycle. The explanation was clear once the reactor was opened and the catalytic bed was sectioned. Catalyst particles were thoroughly broken into a powder. This is likely caused by the repeated compression-decompression cycles, which stress the catalyst structure leading to collapse. Also liquid expansion by $\mathrm{CO}_{2}$ might play a role. However, the catalyst was still active, as observed by the amount of water formed, but the sudden increase of specific surface determined an excessively large contact time. While suggesting that the physical properties of the catalyst particles and metal dispersion deserve investigation, its resistance to pressure cycle is not a limitation in view of a continuous operation.

\section{Conclusions}

Measurements of $\mathrm{H}_{2} \mathrm{O}_{2}$ direct synthesis in a TBR, with $\mathrm{Pd}-\mathrm{CeS}$ catalyst at 10 and 20 bar at $-10{ }^{\circ} \mathrm{C}$, have been reported and discussed. Independent variations of gas and liquid flow rates evidence large, nonlinear effects on both $\mathrm{H}_{2} \mathrm{O}_{2}$ productivity and selectivity, always highlighting an optimum at conditions intermediate within the range investigated. In addition, the role of pressure (from 10 to 20 bar) indicates that a dramatic increase of selectivity, up to values of $80 \%$, can be achieved by raising the pressure. Production rate remains rather poor, mainly because of the competition of direct water synthesis clearly spotted by comparing synthesis with decomposition and hydrogenation experiments, and the short contact time.

Perhaps the most significant conclusion that can be drawn is that the reactor type and operation can dramatically modify (both positively or negatively) the performances of the catalyst. While much of the efforts on improving $\mathrm{H}_{2} \mathrm{O}_{2}$ direct synthesis remain on the catalyst, results reported here suggest that good catalysts can be better exploited in suitable, industrially viable reactors. It is representative in this respect the comparison with semibatch experiments with the same catalyst, ${ }^{14}$ where selectivity was always below $50 \%$ vs the approximately $80 \%$ measured in the TBR at 20 bar with suitable gas and liquid flow rates.

\section{Acknowledgment}

P.B. gratefully acknowledges the PCC (Process Chemistry Centre), Abo Akademi, and the Johan Gadolinian scholarship for financial support.

\section{Literature Cited}

(1) Pralus, C.; Schirmann, J. P. Atochem ELF SA. U.S. Patent 4,996,039, 1991. 
(2) Chuang, K. T. Atomic Energy of Canada Ltd. U.S. Patent 5,082,647, 1992.

(3) Van Weynbergh, J.; Schoebrechts, J. P.; Colery, J. C. Solvay Interox. U.S. Patent 5,447,706, 1995.

(4) Germin, A.; Pirapad, J. P.; Delattre, V.; Van Weynbergh, J.; Vogels, C. Solvay Interox. U.S. Patent 5,500,202, 1996.

(5) Zhou, B.; Lee, L. K. Hydrocarbon Technologies Inc. U.S. Patent 6,168,775, 2001.

(6) Paparatto, G.; Rivetti, F.; Andrigo, P.; De Alberti, G. Eni S.p.A. U.S. Patent 6,649,140, 2003.

(7) Hass, T.; Stochniol, G.; Rollmann, J. Degussa AG. U.S. Patent 6,764,671, 2004.

(8) Hass, T.; Stochniol, G.; Rollmann, J. Degussa AG. U.S. Patent 7,005,528, 2006.

(9) Parasher, S.; Rueter, M.; Zhou, B. Headwaters Nanokinetix Inc. U.S. Patent 7,045,481, 2006.

(10) Rueter, M.; Zhou, B.; Parasher, S. Headwaters Nanokinetix Inc. U.S. Patent 7,144,565, 2006.

(11) Henkel, H.; Weber, W. Henkel \& CIE. U.S. Patent 1,108,752, 1914.

(12) Centi, G.; Perathoner, S.; Abate, S. Direct synthesis of hydrogen peroxide: recent advances. In Modern Heterogeneous Oxidation Catalysis; Wiley-VCH Verlag GmbH\&Co. KGaA: Weinheim, Germany, 2009; pp 253-287.

(13) Brasse, C.; Jaeger, B. Direct synthesis opens up entirely new markets. Degussa Science Newsletter, 2006.

(14) Menegazzo, F.; Burti, P.; Signoretto, M.; Manzoli, M.; Vankova, S.; Boccuzzi, F.; Pinna, F.; Strukul, G. Effect of the addition of Au in zirconia and ceria supported Pd catalysts for the direct synthesis of hydrogen peroxide. J. Catal. 2008, 257, 369-381.

(15) Melada, S.; Rioda, R.; Menegazzo, F.; Pinna, F.; Strukul, G. Direct synthesis of hydrogen peroxide on zirconia-supported catalysts under mild conditions. J. Catal. 2006, 239, 422-430.

(16) Menegazzo, F.; Signoretto, M.; Manzoli, M.; Boccuzzi, F.; Cruciani, G.; Pinna, F.; Strukul, G. Influence of the preparation method on the morphological and composition properties of Pd-Au/ZrO $\mathrm{Zr}_{2}$ catalysts and their effect on the direct synthesis of hydrogen peroxide from hydrogen and oxygen. J. Catal. 2009, 268, 122-130.

(17) Bernardotto, G.; Menegazzo, F.; Pinna, F.; Signoretto, M.; Cruciani, G.; Strukul, G. New Pd-Pt and Pd-Au catalysts for an efficient synthesis of $\mathrm{H}_{2} \mathrm{O}_{2}$ from $\mathrm{H}_{2}$ and $\mathrm{O}_{2}$ under very mild conditions. Appl. Catal., A 2009, $358,129-135$.

(18) Landon, P.; Ferguson, J.; Solsona, B. E.; Garcia, T.; Al-Sayari, S.; Carley, A. F.; Herzing, A.; Hutchings, G. J. Direct Synthesis of Hydrogen Peroxide from $\mathrm{H}_{2}$ and $\mathrm{O}_{2}$ Using $\mathrm{Al}_{2} \mathrm{O}_{3}$ Supported Au-Pd Catalysts. Chem. Mater. 2006, 18, 2689-2695.

(19) Burch, R.; Ellis, P. R. An investigation of alternative catalytic approaches for the direct synthesis of hydrogen peroxide from hydrogen and oxygen. Appl. Catal., B 2003, 42, 203-211.

(20) Samanta, C.; Choudhary, V. R. Direct formation of $\mathrm{H}_{2} \mathrm{O}_{2}$ from $\mathrm{H}_{2}$ and $\mathrm{O}_{2}$ and decomposition/hydrogenation of $\mathrm{H}_{2} \mathrm{O}_{2}$ in aqueous acidic reaction medium over halide-containing $\mathrm{Pd} / \mathrm{SiO}_{2}$ catalytic system. Catal. Commun. 2007, 8, 2222-2228.
(21) Abate, S.; Melada, S.; Centi, G.; Perathoner, S.; Pinna, F.; Strukul, G. Performances of Pd-Me $(\mathrm{Me}=\mathrm{Ag}, \mathrm{Pt})$ catalysts in the direct synthesis of $\mathrm{H}_{2} \mathrm{O}_{2}$ on catalytic membranes. Catal. Today 2006, 117, 193-198.

(22) Abate, S.; Arrigo, R.; Schuster, M. E.; Perathoner, S.; Centi, G.; Villa, A.; Su, D.; Schlögl, R. Pd Nanoparticles supported on N-doped nanocarbon for the direct synthesis of $\mathrm{H}_{2} \mathrm{O}_{2}$ from $\mathrm{H}_{2}$ and $\mathrm{O}_{2}$. Catal. Today 2010; doi: 10.1016/j.cattod.2010.01.027.

(23) Burato, C.; Campestrini, S.; Han, Yi-Fan; Canton, P.; Centomo, P.; Canu, P.; Corain, B. Chemoselective and re-usable heterogeneous catalysts for the direct synthesis of hydrogen peroxide in the liquid phase under non-explosive conditions and in the absence of chemoselectivity enhancers. Appl. Catal., A 2009, 358, 224-231.

(24) Edwards, J. K.; Thomas, A.; Solsona, B. E.; Landon, P.; Carley, A. F.; Hutchings, G. J. Comparison of supports for the direct synthesis of hydrogen peroxide from $\mathrm{H}_{2}$ and $\mathrm{O}_{2}$ using Au-Pd catalysts. Catal. Today 2007, 122, 397-402.

(25) Brieva, G. B.; Serrano, E. C.; Martin, J. M. C.; Fierro, J. L. G. Direct synthesis of hydrogen peroxide solution with palladium-loaded sulfonic acid polystyrene resins. Chem. Commun. 2004, 1184-1185.

(26) Liu, Q.; Lunsford, J. H. The roles of chloride ions in the direct formation of $\mathrm{H}_{2} \mathrm{O}_{2}$ from $\mathrm{H}_{2}$ and $\mathrm{O}_{2}$ over a $\mathrm{Pd} / \mathrm{SiO}_{2}$ catalyst in a $\mathrm{H}_{2} \mathrm{SO}_{4} /$ ethanol system. J. Catal. 2006, 239, 237-243.

(27) Liu, Q.; Lunsford, J. H. Controlling factors in the direct formation of $\mathrm{H}_{2} \mathrm{O}_{2}$ from $\mathrm{H}_{2}$ and $\mathrm{O}_{2}$ over a $\mathrm{Pd} / \mathrm{SiO}_{2}$ catalyst in ethanol. Appl. Catal., A 2006, 314, 94-100.

(28) Liu, Q.; Gath, K. K.; Bauer, J. C.; Schaak, R. E.; Lunsford, J. H. The Active Phase in the Direct Synthesis of $\mathrm{H}_{2} \mathrm{O}_{2}$ from $\mathrm{H}_{2}$ and $\mathrm{O}_{2}$ over $\mathrm{Pd} / \mathrm{SiO}_{2}$ Catalyst in $\mathrm{H}_{2} \mathrm{SO}_{4} /$ Ethanol System. Catal. Lett. 2009, 132, 342348.

(29) Mary, G.; Chaouki, J.; Luck, F. Trickle-Bed Laboratory Reactors for Kinetic Studies. Int. J. Chem. React. Eng. 2009, 7, R2.

(30) Ramachandran, P. A.; Chaudhari, R. V. Topics in Chemical Engineering. Vol. 2: Three-Phase Catalytic Reactors; Gordon and Breach: New York, 1983.

(31) Chinta, S.; Lunsford, J. H. A mechanistic study of $\mathrm{H}_{2} \mathrm{O}_{2}$ and $\mathrm{H}_{2} \mathrm{O}$ formation from $\mathrm{H}_{2}$ and $\mathrm{O}_{2}$ catalyzed by palladium in an aqueous medium. J. Catal. 2004, 225, 249-255.

(32) Lunsford, J. H. The direct formation of $\mathrm{H}_{2} \mathrm{O}_{2}$ from $\mathrm{H}_{2}$ and $\mathrm{O}_{2}$ over palladium catalysts. J. Catal. 2003, 216, 455-460.

(33) Samanta, C.; Choudhary, V. R. Direct oxidation of $\mathrm{H}_{2}$ to $\mathrm{H}_{2} \mathrm{O}_{2}$ over $\mathrm{Pd} / \mathrm{Ga}_{2} \mathrm{O}_{3}$ catalyst under ambient conditions: Influence of halide ions added to the catalyst or reaction medium. Appl. Catal., A 2007, 326, 28 36.

(34) Jessop, P. G.; Subramaniam, B. Gas-Expanded Liquids. Chem. Rev. 2007, 107, 2666-2694.

(35) Choudhary, V. R.; Samanta, C.; Choudhary, T. V. Direct oxidation of $\mathrm{H}_{2}$ to $\mathrm{H}_{2} \mathrm{O}_{2}$ over Pd-based catalysts: Influence of oxidation state, support and metal additives. Appl. Catal., A 2006, 308, 128-133.

Received for review March 8, 2010

Revised manuscript received August 24, 2010 Accepted August 25, 2010

IE100550K 